\title{
Effects of volume resuscitation on splanchnic perfusion in canine model of severe sepsis induced by live Escherichia coli infusion
}

\author{
Claudio Esteves Lagoa ${ }^{1}$, Luiz Francisco Poli de Figueiredo², Ruy Jorge Cruz Jr³ ${ }^{3}$ Eliézer Silva ${ }^{4}$ and \\ Maurício Rocha e Silva ${ }^{5}$
}

\begin{abstract}
1DVM, Fellow, Division of Applied Physiology, Heart Institute (InCor), University of São Paulo Medical School, São Paulo, Brazil ${ }^{2}$ Associate Professor, Division of Applied Physiology, Heart Institute (InCor), University of São Paulo Medical School, São Paulo, Brazil ${ }^{3}$ Assistant Physician, Division of Applied Physiology, Heart Institute (InCor), University of São Paulo Medical School, São Paulo, Brazil 4Visiting Professor, Division of Applied Physiology, Heart Institute (InCor), University of São Paulo Medical School, São Paulo, Brazil ${ }^{5}$ Chairman, Division of Applied Physiology, Heart Institute (InCor), University of São Paulo Medical School, São Paulo, Brazil
\end{abstract}

Corresponding author: Luiz Francisco Poli de Figueiredo, Ipoli@uol.com.br

Received: 30 October 2003

Revisions requested: 22 December 2003

Revisions received: 14 April 2004

Accepted: 21 April 2004

Published: 27 May 2004
Critical Care 2004, 8:R221-R228 (DOI 10.1186/cc2871)

This article is online at: http://ccforum.com/content/8/4/R221

(C) 2004 Lagoa et al.; licensee BioMed Central Ltd. This is an Open Access article: verbatim copying and redistribution of this article are permitted in all media for any purpose, provided this notice is preserved along with the article's original URL.

\begin{abstract}
Introduction We conducted the present study to investigate whether early large-volume crystalloid infusion can restore gut mucosal blood flow and mesenteric oxygen metabolism in severe sepsis.

Methods Anesthetized and mechanically ventilated male mongrel dogs were challenged with intravenous injection of live Escherichia coli ( $6 \times 10^{9}$ colony-forming units/ml per kg over $\left.15 \mathrm{~min}\right)$. After 90 min they were randomly assigned to one of two groups - control (no fluids; $n=13$ ) or lactated Ringer's solution (32 $\mathrm{ml} / \mathrm{kg}$ per hour; $n=14$ ) - and followed for $60 \mathrm{~min}$. Cardiac index, mesenteric blood flow, mean arterial pressure, systemic and mesenteric oxygen-derived variables, blood lactate and gastric carbon dioxide tension $\left(\mathrm{PCO}_{2}\right.$; by gas tonometry) were assessed throughout the study.

Results $E$. coli infusion significantly decreased arterial pressure, cardiac index, mesenteric blood flow, and systemic and mesenteric oxygen delivery, and increased arterial and portal lactate, intramucosal $\mathrm{PCO}_{2}, \mathrm{PCO}_{2}$ gap (the difference between gastric mucosal and arterial $\mathrm{PCO}_{2}$ ), and systemic and mesenteric oxygen extraction ratio in both groups. The Ringer's solution group had significantly higher cardiac index and systemic oxygen delivery, and lower oxygen extraction ratio and $\mathrm{PCO}_{2}$ gap at 165 min as compared with control animals. However, infusion of lactated Ringer's solution was unable to restore the $\mathrm{PCO}_{2}$ gap. There were no significant differences between groups in mesenteric oxygen delivery, oxygen extraction ratio, or portal lactate at the end of study.

Conclusion Significant disturbances occur in the systemic and mesenteric beds during bacteremic severe sepsis. Although large-volume infusion of lactated Ringer's solution restored systemic hemodynamic parameters, it was unable to correct gut mucosal $\mathrm{PCO}_{2}$ gap.
\end{abstract}

Keywords: gas tonometry, live E. coli, mesenteric blood flow, oxygen metabolism, severe sepsis

\section{Introduction}

Sepsis leads to endothelial damage, marked alterations in blood flow distribution and altered tissue oxygen metabolism, which are associated with high mortality rates among critically ill patients [1-3]. Although volume replacement is among the cornerstones of therapy for septic shock [4], studies conducted to elucidate the actual impact of fluid infusion on both experimental and clinical sepsis with respect to systemic endpoints of resuscitation and outcome are inconsistent [5-8]. This is largely because of the wide variety of experimental designs and fluid regimens employed.

Substantial clinical and animal evidence indicates that the mesenteric circulatory bed, particularly at the gut mucosa, is 
highly vulnerable to reductions in oxygen supply and is prone to injury early in the course of shock [9-11]. Gut hypoxia or ischemia is one factor that possibly contributes to dysfunction of the gastrointestinal tract barrier, which may in turn contribute to the development of systemic inflammatory response and multiple organ dysfunction syndromes [12-15].

Although bolus injection of live bacteria has potential downsides [16], it may mimic the very early hemodynamic phase of severe sepsis, and serve to illustrate how systemic and regional blood flows react to aggressive and prompt fluid replacement. Interesting results have recently been reported in patients with sepsis resuscitated in the emergency room [17] based on central venous oxygen saturation. However, the disparity between systemic and regional variables has been well demonstrated, particularly in such a complex disease as sepsis, with a wide variety of clinical presentations and resuscitation protocols employed in clinical and experimental studies of shock. In the majority of experimental studies, fluid infusion did not restore intestinal mucosal perfusion, even though systemic and mesenteric parameters were improved $[18,19]$. In a recent clinical study conducted in patients with sepsis [20], a wide interindividual variability in carbon dioxide tension $\left(\mathrm{PCO}_{2}\right)$ gap in response to fluid loading was observed.

Our hypothesis is that, despite restoring systemic hemodynamic and oxygen derived variables, large-volume crystalloid infusion fails to restore gut mucosal blood flow and $\mathrm{PCO}_{2}$ gap in animals challenged with infusion of live bacteria. Hence, we evaluated the impact of this early volume resuscitation on the systemic and splanchnic circulations in a model of severe sepsis.

\section{Methods}

The present study was approved by the Animal Care and Use Committee of the University of São Paulo Medical School, and was conducted in compliance with the guidelines of the National Regulations for the Care and Use of Laboratory Animals.

\section{Animal preparation}

Twenty-seven healthy male mongrel dogs (weight $17.2 \pm 1.2$ $\mathrm{kg}$ ) were fasted for 12 hours before the start of the study and were given free access to water. Anesthesia was induced with an intravenous injection of $0.06 \mathrm{mg} / \mathrm{kg}$ morphine sulfate, followed by $25 \mathrm{mg} / \mathrm{kg}$ sodium pentobarbital. A cuffed endotracheal tube was placed into the trachea to allow mechanical ventilation with $100 \%$ oxygen, at a tidal volume of $20 \mathrm{ml} / \mathrm{kg}$ (Takaoka 2600, Takaoka Ltda, São Paulo, SP, Brazil). Respiratory rate was adjusted to maintain arterial $\mathrm{PCO}_{2}$ at $35 \pm 5$ $\mathrm{mmHg}$. A heating pad was used to maintain the core body temperature at $38.5 \pm 1.0^{\circ} \mathrm{C}$. Additional doses of pentobarbital $(2 \mathrm{mg} / \mathrm{kg})$ were administered whenever required. A urinary catheter was placed for urine drainage. Each dog received an intravenous injection of $300 \mathrm{mg}$ cimetidine.
The right common femoral artery was dissected and cannulated with a polyethylene catheter to measure mean arterial pressure at the abdominal aorta and to collect arterial blood samples for blood gas and lactate analysis. A catheter was introduced through the right common femoral vein for fluid infusion. Each animal received an infusion of lactated Ringer's solution $(13 \mathrm{ml} / \mathrm{kg})$ during the preparation period.

A 7.5-Fr flow-directed thermodilution fiberoptic pulmonary artery catheter (Edwards Swan-Ganz CCOmbo 744H7.5F; Baxter Edwards Critical Care, Irvine, CA, USA) was introduced through the right external jugular vein. The tip was placed in the pulmonary artery, guided by radioscopy and wave tracings, to measure pulmonary arterial pressures, continuous mixed venous oxygen saturation $\left(\mathrm{SVO}_{2}\right)$, and for mixed venous sampling for blood gas analysis. This catheter was connected to a cardiac computer (Vigilance $^{\mathrm{TM}}$; Baxter Edwards Critical Care) to measure cardiac output using 3-ml bolus injections of isotonic saline at $20^{\circ} \mathrm{C}$ every $10 \mathrm{~min}$. All catheters were connected to disposable pressure transducers (P23XL; Viggo-Spectramed, Stathan, CA, USA) and to a computerized multichannel system for acquisition of biologic data (Acknowledge; Biopac Systems Inc., Goleta, CA, USA).

A left subcostal celiotomy was performed and an ultrasonic flow probe (Transonic Systems Inc., Ithaca, NY, USA) was placed around the origin of the superior mesenteric artery for measurement of transit time flow in this vessel (model T206; Transonic Systems Inc.). A P240 catheter was threaded into the portal system via the splenic vein for portal blood sampling. A large gastric polyethylene tube was introduced through the mouth and placed in the stomach, and a gastric lavage was performed with warm isotonic saline solution until a clear fluid was obtained at drainage. Then, a 16-Fr TRIP ${ }^{\circledR}$ tonometry catheter (TRIP ${ }^{\circledR}$ NGS, Tonometrics Division, Instrumentarium Copr., Helsinki, Finland.) was introduced orally and positioned at the large curvature of the stomach. The tonometry catheter was connected to a calibrated gas capnometer (Tonocap, model TC-200; Tonometrics, Datex-Engstrom, Finland) for gastric $\mathrm{PCO}_{2}$ measurement.

\section{Bacterial preparation}

A strain of Escherichia coli O55B, provided by the Adolfo Lutz Institute of Infectious Diseases, originating from the stool of a patient with gastrointestinal sepsis, was used in the study. The bacteria were stored in gelose at room temperature, activated in trypticase soy broth, plated in trypticase soy agar and incubated at $36^{\circ} \mathrm{C}$ for 24 hours. Aliquots were then suspended in sterile saline. The bacterial suspension was estimated turbidimetrically by comparing the newly grown bacterial suspension with known standards through spectophotometry at a wavelength of $625 \mathrm{~nm}$, in order to obtain a culture of the desired bacterial density. The same suspension was subsequently quantified by plating successive 10 -fold dilutions onto trypticase soy agar plates and scoring visible colonies after 24 
hours of incubation at $36^{\circ} \mathrm{C}$. Our target dose, as calculated using the methods outlined above, was $3 \times 10^{9} \mathrm{cells} / \mathrm{ml}$ or 6 $\times 10^{9}$ colony-forming units $/ \mathrm{ml}$ per kg body weight.

\section{Data collection and analysis}

Mean arterial pressure, pulmonary artery and central venous pressures, heart rate and mesenteric blood flow were continuously recorded. Pulmonary artery occluded pressure was measured at every time point. Cardiac output was determined using thermodilution technique and expressed as cardiac index according to the dog's body surface area. Each determination was the arithmetic mean of three consecutive measurements when their differences did not exceed $10 \%$.

Arterial, portal and mixed venous base deficit, $\mathrm{pH}, \mathrm{PCO}_{2}$, oxygen tension, oxygen saturation, hemoglobin, hematocrit, bicarbonate, and lactate levels were measured at baseline, and then at $15,45,75,105,135$ and 165 min during the experimental protocol. All arterial, venous, and portal blood samples were analyzed by a Stat Profile Ultra Analyzer (Nova Biomedical, Waltham, MA, USA). Systemic and mesenteric oxygen delivery $\left(\mathrm{DO}_{2}\right)$ and systemic and mesenteric oxygen extraction ratio $\left(\mathrm{O}_{2} \mathrm{ER}\right)$ were calculated using standard formulae.

Systemic venous-arterial $\mathrm{PCO}_{2}$ gradient was calculated as the difference between mixed venous $\mathrm{PCO}_{2}$ and arterial $\mathrm{PCO}_{2}$. Portal-arterial $\mathrm{PCO}_{2}$ gradient was calculated as the difference between portal vein $\mathrm{PCO}_{2}$ and arterial $\mathrm{PCO}_{2}$. Gastric mucosal $\mathrm{PCO}_{2}$ was evaluated every $10 \mathrm{~min}$. $\mathrm{PCO}_{2}$ gap was calculated as the difference between gastric mucosal and arterial $\mathrm{PCO}_{2}$.

\section{Experimental protocol}

After surgical preparation, animals were allowed to stabilize for $30 \mathrm{~min}$. After baseline measurements ( $0 \mathrm{~min}$ ), an infusion of $E$. coli at a dose of $6 \times 10^{9}$ colony-forming units $/ \mathrm{ml}$ per $\mathrm{kg}$ was started and maintained for $15 \mathrm{~min}$. At $90 \mathrm{~min}$ after bacterial infusion (S105), the animals were randomly assigned to two groups. Control animals $(n=13)$ received no fluids and were followed for $60 \mathrm{~min}$ with no additional intervention. Treated animals $(n=14)$ received lactated Ringer's solution (32 $\mathrm{ml} / \mathrm{kg}$ per hour) and were also followed for $60 \mathrm{~min}$. All animals were killed at the end of the experimental protocol (R165) by an overdose of anesthetic followed by injection of hypertonic potassium chloride.

\section{Statistical analysis}

Results are expressed as mean \pm standard error of the mean. Statistical analysis was performed using the Statistical Package for Social Sciences for Windows (version 6.0; SPSS Inc., Chicago, IL, USA). Two-way analysis of variance for repeated measures and post hoc Tukey's test were used to analyze differences between groups. Comparisons of values at different time points within groups were performed using analysis of variance for repeated measures. $P<0.05$ was considered statistically significant.

\section{Results \\ Systemic effects of live Escherichia coli infusion and fluid replacement}

The infusion of live $E$. coli promoted significant reductions in mean arterial pressure, cardiac index, $\mathrm{DO}_{2}$, and $\mathrm{SVO}_{2}$. In parallel, increases in oxygen extraction rate, venous-arterial $\mathrm{PCO}_{2}$ gradient and arterial lactate were detected (Figs 1 and 2; Table 1).

In untreated control animals hemoglobin levels exhibited a sustained increase. Mean arterial pressure exhibited a spontaneous, partial, and progressive increase. No other systemic variable showed such a trend toward recovery within $150 \mathrm{~min}$ after the end of bacterial infusion (Figs 1 and 2; Table 1).

Fluid replacement was associated with an increase in mean arterial pressure, similar to that observed in untreated control animals. Other systemic variables (i.e. cardiac index, $\mathrm{DO}_{2}$, and $\mathrm{SVO}_{2}$ ) were restored to baseline values, and were significantly greater than those in control animals. Arterial lactate remained elevated after fluid infusion, at levels similar to those in control animals (Figs 1 and 2; Table 1).

\section{Regional effects of live Escherichia coli infusion and fluid replacement}

Live $E$. coli infusion resulted in marked reductions in mesenteric blood flow, mesenteric $\mathrm{DO}_{2}$ and portal $\mathrm{SVO}_{2}$, whereas significant increases in mesenteric $\mathrm{O}_{2} \mathrm{ER}$, portal lactate and portal-arterial $\mathrm{PCO}_{2}$ gradients were observed (Fig. 2; Table 2). Control animals exhibited a spontaneous increase in mesenteric blood flow and mesenteric $\mathrm{DO}_{2}$, whereas portal lactate and portal oxygen saturation showed no significant changes. Treated animals exhibited only a partial increase in mesenteric blood flow. Fluid infusion was unable to restore the other regional variables. $\mathrm{PCO}_{2}$ gap began to increase progressively after bacterial infusion. At 105 min the $\mathrm{PCO}_{2}$ gap had increased by approximately 150\% $(P<0.0001)$ in both groups (Fig. 2) and showed a sustained increase in control animals. Fluid replacement prevented further increases in the $\mathrm{PCO}_{2}$ gap but was unable to reverse the increase, which remained significantly greater than at baseline but was lower than that in control animals.

\section{Discussion}

This model of severe sepsis satisfactorily matched the hemodynamic changes that are characteristic of a nonresuscitated, hypodynamic septic patient. Live $E$. coli injection promoted reductions in cardiac output, mean arterial pressure, and mesenteric blood flow. These alterations were paralleled by increases in systemic venous-arterial, portal-arterial and gastric mucosal-arterial $\mathrm{PCO}_{2}$ gradients, thus reflecting the blood flow disturbances induced by the challenge with live bacteria. 
Figure 1

(a) mean arterial pressure

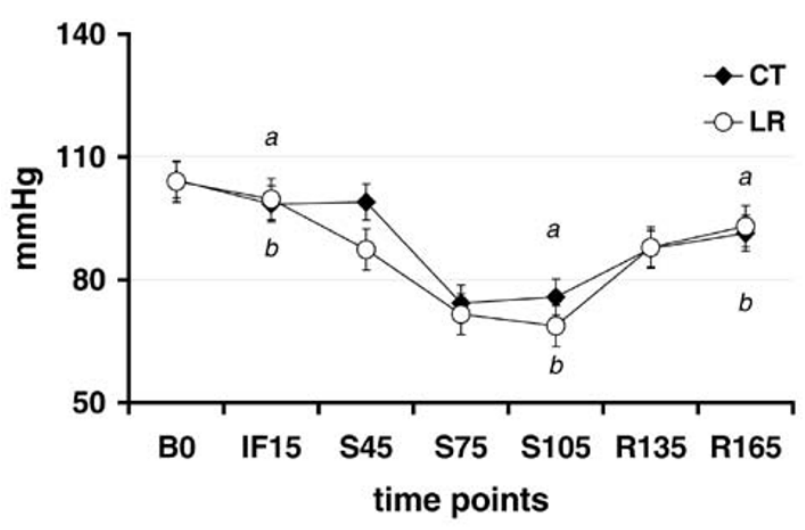

(b) cardiac index

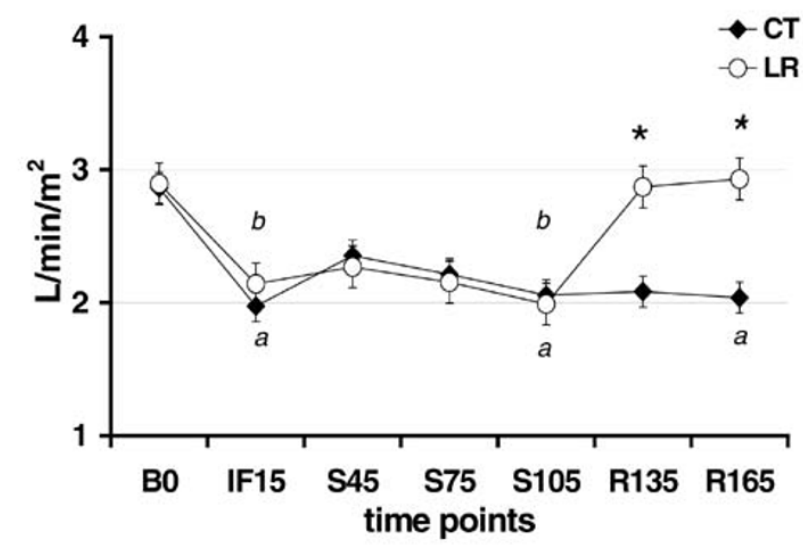

(a) Mean arterial pressure and (b) cardiac index. Data are expressed as mean \pm standard error of the mean. B0, baseline; IF15, 15 min after bacterial infusion; S45-S105, shock, 45-105 min after B0; R135R165, resuscitation period. ${ }^{*} P<0.05$ control (CT) versus baseline; ${ }^{\dagger} P$ $<0.05$ lactated Ringer's solution (LR) versus baseline; $¥ P<0.05 \mathrm{CT}$ versus $L R$.

The main finding in the study is that large-volume crystalloid resuscitation failed to correct the oxygen debt established in the mesenteric circulation, particularly gut mucosal blood flow, even though systemic hemodynamic and oxygen-derived parameters were restored.

Although several studies have shown that endotoxin infusion is associated with marked decreases in cardiac output and mesenteric blood flow, and with an increase in gastric mucosal $\mathrm{PCO}_{2}$ [21-23], data from experiments involving infusion of live bacteria are scarce. In our model infusions of viable bacteria reproduced many of the features of early severe sepsis in humans, including hypotension, hyperlactatemia, and oliguria. The inflammatory response to infusion of viable bacteria can
Figure 2

(a) mesenteric blood flow

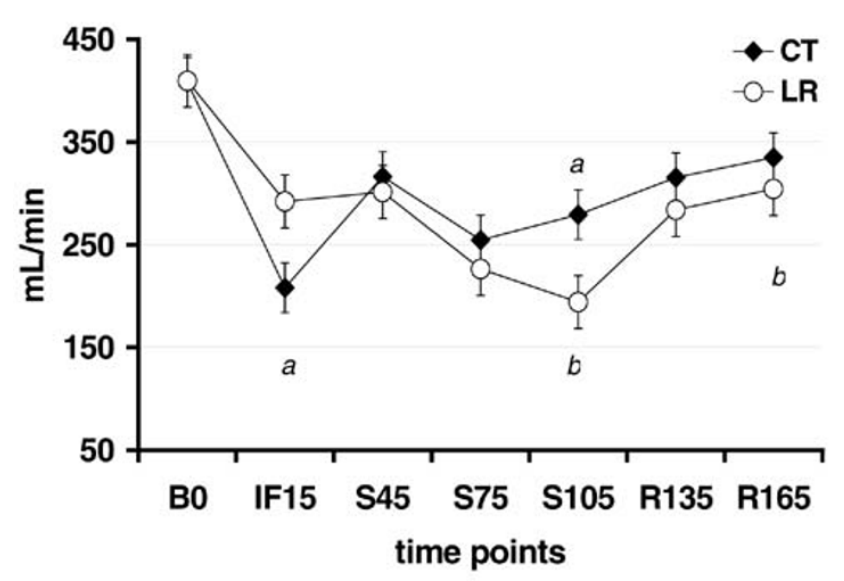

(b)
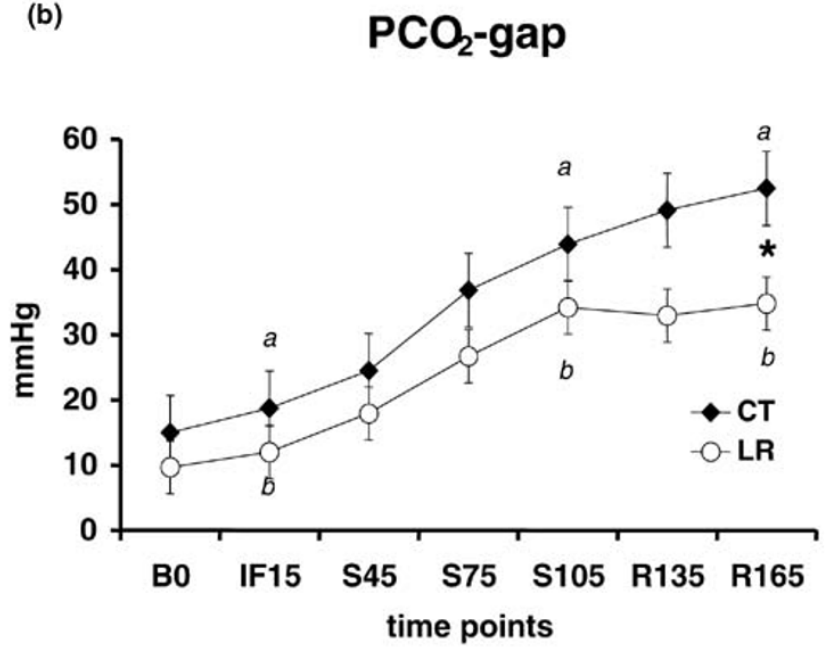

(a) Superior mesenteric artery blood flow and (b) carbon dioxide tension $\left(\mathrm{PCO}_{2}\right)$ gap. Data are expressed as mean \pm standard error of the mean. B0, baseline; IF15, 15 min after bacterial infusion; S45-S105, shock, 45-105 min after B0; R135-R165, resuscitation period. ${ }^{*} P<$ 0.05 control $(\mathrm{CT})$ versus baseline; ${ }^{\dagger} P<0.05$ lactated Ringer's solution (LR) versus baseline; ${ }^{\ddagger} P<0.05 \mathrm{CT}$ versus $\mathrm{LR}$.

be more pronounced than that produced by endotoxin infusions [16]. This model is less expensive than endotoxin infusion in large animals, and it induces a more severe hemodynamic compromise with a low early mortality rate, mimicking severe sepsis after bacteremia. Hence, it is a very useful tool for improving our understanding of the earliest stages in bacteremic sepsis. Models that allow more prolonged observation of infection, such as intraperitoneal clot or cecum puncture and ligation, could better represent most clinical conditions. However, we aimed for a model that induces rapid and profound changes, such as those that are seen in bloodstream infections, thus allowing us to address the effects of 
Table 1

Central venous and pulmonary artery occluded pressures, systemic oxygen-derived variables, arterial lactate, pH and hemoglobin

\begin{tabular}{|c|c|c|c|c|c|}
\hline \multirow[t]{2}{*}{ Parameter } & \multirow[t]{2}{*}{ Baseline } & \multicolumn{4}{|c|}{ Minutes after bacterial infusion } \\
\hline & & 15 & 90 & 120 & 150 \\
\hline \multicolumn{6}{|l|}{ CVP $(\mathrm{mmHg})$} \\
\hline Control & $3.7 \pm 0.4$ & $4.0 \pm 0.4$ & $2.7 \pm 0.5$ & $2.4 \pm 0.5$ & $2.7 \pm 0.5$ \\
\hline Lactated Ringer's & $3.3 \pm 0.5$ & $2.8 \pm 0.5$ & $2.4 \pm 0.5$ & $4.2 \pm 0.8$ & $4.9 \pm 0.8$ \\
\hline \multicolumn{6}{|l|}{ PAOP $(\mathrm{mmHg})$} \\
\hline Control & $6.1 \pm 0.5$ & $5.3 \pm 0.8$ & $4.0 \pm 0.5$ & $4.2 \pm 0.6$ & $4.3 \pm 0.6$ \\
\hline Lactated Ringer's & $4.4 \pm 0.5$ & $4.1 \pm 0.6$ & $4.4 \pm 0.6$ & $5.0 \pm 0.7$ & $4.9 \pm 0.5$ \\
\hline \multicolumn{6}{|l|}{$\mathrm{pH}$} \\
\hline Control & $7.416 \pm 0.01$ & $7.416 \pm 0.01$ & $7.416 \pm 0.01$ & $7.416 \pm 0.01$ & $7.416 \pm 0.01$ \\
\hline Lactated Ringer's & $7.424 \pm 0.01$ & $7.406 \pm 0.01$ & $7.384 \pm 0.01$ & $7.384 \pm 0.01$ & $7.408 \pm 0.01$ \\
\hline \multicolumn{6}{|l|}{ Hemoglobin (g/dl) } \\
\hline Control & $12.2 \pm 0.5$ & $12.5 \pm 0.5$ & $13.7 \pm 0.3$ & $14.0 \pm 0.3^{\star \neq}$ & $14.2 \pm 0.4^{\star \ddagger}$ \\
\hline Lactated Ringer's & $12.6 \pm 0.4$ & $12.8 \pm 0.5$ & $13.8 \pm 0.5$ & $12.1 \pm 0.5$ & $11.5 \pm 0.6$ \\
\hline \multicolumn{6}{|l|}{$\mathrm{DO}_{2}(\mathrm{ml} / \mathrm{min})$} \\
\hline Control & $402.6 \pm 27.3$ & $284.9 \pm 25.1^{*}$ & $321.7 \pm 36.7^{\star}$ & $328.7 \pm 37^{\star}$ & $325.3 \pm 28.4^{*}$ \\
\hline Lactated Ringer's & $432.8 \pm 30.7$ & $322.3 \pm 25.1^{\dagger}$ & $320.9 \pm 29.4^{\dagger}$ & $404.5 \pm 21.8$ & $395.4 \pm 28.3$ \\
\hline \multicolumn{6}{|l|}{$\mathrm{O}_{2} \mathrm{ER}(\%)$} \\
\hline Control & $23.9 \pm 2.1$ & $30.5 \pm 2.5^{*}$ & $33.1 \pm 3.0^{*}$ & $28.8 \pm 2.8^{\star}$ & $32.5 \pm 2.8^{*}$ \\
\hline Lactated Ringer's & $23.8 \pm 3.0$ & $26.9 \pm 3.7$ & $33.1 \pm 5.6^{+}$ & $26.7 \pm 2.5$ & $23.3 \pm 2.3^{\ddagger}$ \\
\hline \multicolumn{6}{|l|}{$\mathrm{SVO}_{2}(\%)$} \\
\hline Control & $80.1 \pm 2.3$ & $69.7 \pm 2.5^{\star}$ & $67.4 \pm 3.4^{*}$ & $71.6 \pm 3.2^{*}$ & $67.6 \pm 3.0^{*}$ \\
\hline Lactated Ringer's & $78.6 \pm 3.2$ & $73.6 \pm 3.8^{+}$ & $66.8 \pm 5.7^{+}$ & $76.7 \pm 2.6^{+}$ & $77.2 \pm 2.3^{\ddagger}$ \\
\hline \multicolumn{6}{|l|}{ Arterial lactate $(\mathrm{mmol} / \mathrm{l})$} \\
\hline Control & $1.58 \pm 0.49$ & $1.62 \pm 0.39$ & $3.73 \pm 0.34^{*}$ & $3.48 \pm 0.29^{\star}$ & $3.31 \pm 0.25^{\star}$ \\
\hline Lactated Ringer's & $1.57 \pm 0.24$ & $1.85 \pm 0.23$ & $4.01 \pm 0.65^{\dagger}$ & $4.22 \pm 0.59^{\dagger}$ & $3.44 \pm 0.51^{\dagger}$ \\
\hline \multicolumn{6}{|c|}{ Veno-arterial $\mathrm{PCO}_{2}$ gradient $(\mathrm{mmHg})$} \\
\hline Control & $4.9 \pm 1.0$ & $8.4 \pm 1.2$ & $12.6 \pm 2.0^{*}$ & $9.3 \pm 1.7^{\star}$ & $9.8 \pm 2.0^{*}$ \\
\hline Lactated Ringer's & $6.9 \pm 1.0$ & $8.8 \pm 1.5$ & $9.7 \pm 1.5$ & $5.8 \pm 1.2$ & $6.2 \pm 0.8$ \\
\hline
\end{tabular}

Measurements were taken in control animals $(n=13)$ and animals treated with lactated Ringer's solution $(n=14)$. Data are expressed as mean \pm standard error of the mean. CVP, central venous pressure; $\mathrm{DO}_{2}$, systemic oxygen delivery; $\mathrm{O}_{2} \mathrm{ER}$, systemic oxygen extraction ratio; PAOP, pulmonary artery occluded pressure; $\mathrm{PCO}_{2}$, carbon dioxide tension; $\mathrm{SVO}_{2}$, mixed venous oxygen saturation. ${ }^{\star} P<0.05$, control versus baseline; ${ }^{t} P<0.05$ lactated Ringer's versus baseline; $¥ P<0.05$ control versus lactated Ringer's.

early interventions (i.e. fluid infusion) in the absence of other confounding factors.

The observed increase in venous-arterial $\mathrm{PCO}_{2}$ gradient reflected the reduction in cardiac output, whereas the increase in portal-arterial $\mathrm{PCO}_{2}$ gradient paralleled mesenteric blood flow. However, the $\mathrm{PCO}_{2}$ gap did not parallel systemic and regional blood flow trends. Hence, the distri- bution of blood flow within the gut wall cannot be determined by following regional flow distribution.

The $\mathrm{PCO}_{2}$ gap is often considered an index of splanchnic perfusion, but this has never been demonstrated conclusively. Some experimental and clinical studies have failed to demonstrate a linear correlation between gut mucosal $\mathrm{PCO}_{2}$ and hepatosplanchnic blood flow [24,25]. The $\mathrm{PCO}_{2}$ gap 
Table 2

Regional oxygen-derived variables and portal vein lactate

\begin{tabular}{|c|c|c|c|c|c|}
\hline \multirow[t]{2}{*}{ Parameter } & \multirow[t]{2}{*}{ Baseline } & \multicolumn{4}{|c|}{ Minutes after bacterial infusion } \\
\hline & & 15 & 90 & 120 & 150 \\
\hline \multicolumn{6}{|c|}{ Mesenteric $\mathrm{DO}_{2}(\mathrm{ml} / \mathrm{min})$} \\
\hline Control & $71.6 \pm 8.5$ & $37.7 \pm 3.9^{\star}$ & $54.4 \pm 9.6^{*}$ & $61.7 \pm 10.6$ & $66.6 \pm 11.2$ \\
\hline Lactated Ringer's & $74.3 \pm 9.1$ & $53.5 \pm 7.1^{\dagger}$ & $37.9 \pm 5.2^{+}$ & $47.8 \pm 4.2^{+}$ & $48.2 \pm 4.7^{\dagger}$ \\
\hline \multicolumn{6}{|l|}{ Mesenteric $\mathrm{O}_{2} \mathrm{ER}(\%)$} \\
\hline Control & $15.1 \pm 1.8$ & $23.6 \pm 3.1^{*}$ & $32.7 \pm 3.7^{\star}$ & $29.7 \pm 4.5^{\star}$ & $28.3 \pm 3.5^{\star}$ \\
\hline Lactated Ringer's & $15.6 \pm 2.8$ & $19.8 \pm 2.6^{\dagger}$ & $27.9 \pm 2.8^{+}$ & $22.3 \pm 2.1^{\dagger}$ & $24.5 \pm 2.3^{\dagger}$ \\
\hline \multicolumn{6}{|l|}{$\mathrm{SpO}_{2}(\%)$} \\
\hline Control & $88.3 \pm 1.6$ & $75.9 \pm 3.1^{\star}$ & $67.5 \pm 3.9^{*}$ & $71.9 \pm 4.8^{*}$ & $71.7 \pm 3.4^{\star}$ \\
\hline Lactated Ringer's & $87.9 \pm 2.1$ & $80.2 \pm 1.9^{\dagger}$ & $72.4 \pm 3.3^{+}$ & $80.5 \pm 2.1^{\dagger}$ & $77.4 \pm 2.2^{\dagger}$ \\
\hline \multicolumn{6}{|c|}{ Portal vein lactate $(\mathrm{mmol} / \mathrm{l})$} \\
\hline Control & $1.56 \pm 0.44$ & $1.67 \pm 0.37^{\star}$ & $3.65 \pm 0.32^{*}$ & $3.31 \pm 0.35^{\star}$ & $3.32 \pm 0.28^{*}$ \\
\hline Lactated Ringer's & $1.58 \pm 0.21$ & $1.88 \pm 0.22^{\dagger}$ & $3.97 \pm 0.54^{\dagger}$ & $4.01 \pm 0.52^{\dagger}$ & $3.55 \pm 0.44^{\dagger}$ \\
\hline \multicolumn{6}{|c|}{ Portal-arterial $\mathrm{PCO}_{2}$ gradient $(\mathrm{mmHg})$} \\
\hline Control & $3.6 \pm 1.0$ & $7.9 \pm 1.4^{*}$ & $11.1 \pm 1.2^{*}$ & $9.3 \pm 2.1^{*}$ & $9.6 \pm 1.4^{\star}$ \\
\hline Lactated Ringer's & $4.9 \pm 0.9$ & $8.7 \pm 1.4^{\dagger}$ & $11.1 \pm 1.6^{+}$ & $6.7 \pm 1.7^{\dagger}$ & $7.5 \pm 1.2^{\dagger}$ \\
\hline
\end{tabular}

Measurements were taken in control animals $(n=13)$ and animals treated with lactated Ringer's solution $(n=14)$. Data are expressed as mean \pm standard error of the mean. $\mathrm{DO}_{2}$, oxygen delivery; $\mathrm{O}_{2} \mathrm{ER}$, oxygen extraction ratio; $\mathrm{PCO}_{2}$, carbon dioxide tension; $\mathrm{SpO}$, portal vein oxygen saturation. ${ }^{\star} P<0.05$, control versus baseline; ${ }^{\dagger} P<0.05$ lactated Ringer's versus baseline.

merely reflects perfusion and/or oxygenation conditions of the gut mucosa. Therefore, we cannot extend gut mucosal carbon dioxide measurements to the entire splanchnic area, because blood flow distribution varies widely between and within organs, especially in sepsis. The peculiar microcirculatory system and its countercurrent exchange of oxygen and carbon dioxide within the mucosal villus could explain these findings. Because of these factors, techniques specially designed to assess mucosal blood flow, such as laser Doppler flowmetry [26], reflectance spectroscopy [27], and intravital microscopy [28], are the methods of choice for studying flow derangements associated with intramucosal acidosis. Also, gastric mucosal acidosis may not reflect blood flow reduction, but only oxygen impairment at the cellular level, which has been termed cytopathic hypoxia [29]. This may explain the coexistance of high tissue $\mathrm{PCO}_{2}$ with adequate tissue oxygen tension and small intestine wall blood flow that has been observed by some authors [30]. In fact, a high gastric-arterial $\mathrm{PCO}_{2}$ gradient could be a marker of dysoxia, irrespective of the causes of impaired oxygen utilization, although blood flow is always the major determinant of this gradient.

Our fluid challenge regimen efficiently restored cardiac index, systemic oxygen delivery, and $\mathrm{SVO}_{2}$ to prechallenge measures. In the study, mesenteric $\mathrm{O}_{2} \mathrm{ER}$, portal lactate, and $\mathrm{PCO}_{2}$ gap remained significantly elevated throughout the experiment in both groups. As in the report by Baum and coworkers [31], our results also indicate that intravascular volume expansion alone was incapable of correcting gut mucosal acidosis. Our findings are in agreement with those from other clinical and experimental studies [32,33] that have demonstrated that gut hypoperfusion and acidosis occur rapidly after a septic challenge, despite normal mean arterial pressure, and elevated cardiac output and blood flow. From the therapeutical standpoint, though, it is surprising that large-volume crystalloid infusions had no major impact on total gut blood flow, $\mathrm{DO}_{2}$, and mucosal acidosis as compared with controls. In fact, Drazenovic and coworkers [34] demonstrated that an endotoxin challenge can lead to a small but significant reduction in the density of perfused capillaries in the intestinal mucosal villi and crypts. This may explain the apparent loss of the relationship between oxygen availability and gut perfused capillary density found in that study. These data further demonstrate that variables of systemic cardiopulmonary function, and even the level of mesenteric $\mathrm{DO}_{2}$, may be poor indicators of the intestinal mucosal perfusion status.

Changes in blood rheologic properties, derangement in the number of perfused capillaries, and alterations in microcirculatory blood flow to the gut mucosa may explain why large-volume crystalloid infusion was ineffective in correcting intramucosal $\mathrm{PCO}_{2}$ gap and oxygen metabolism to preshock 
values in the present study. Previously, Fink and coworkers [35] showed that intravascular volume expansion and massive doses of dobutamine ameliorate, but do not completely prevent, the development of mucosal acidosis in endotoxemic pigs.

Our data support the feasibility and usefulness of gastric $\mathrm{PCO}_{2}$ monitoring for detecting gut mucosal malperfusion and ischemia, even in 'normodynamic, resuscitated' severe septic individuals. It also indicates that careful monitoring of mesenteric perfusion is of paramount importance in critically ill individuals. Failure to notice incomplete splanchnic resuscitation in critically ill patients has been correlated with multiple organ system dysfunction, prolonged length of stay in the intensive care unit, and death [36].

\section{Conclusion}

Significant disturbances occur in the systemic and mesenteric bed during bacteremic severe sepsis. Although large-volume lactated Ringer's infusion restored systemic hemodynamic parameters, it was unable to correct gut mucosal $\mathrm{PCO}_{2}$ gap.

\section{Competing interests}

None declared.

\section{Key messages}

In dogs with bacteremic severe sepsis induced by intravenous live $E$. coli, early large-volume crystalloid infusion restored systemic and most regional hemodynamic parameters, but failed to correct increased arterial-gastric $\mathrm{PCO}_{2}$-gap.

\section{Acknowledgments}

This study was supported by grants \#98/06459-3 and \#98/06458-7 from FAPESP - Fundação de Amparo à Pesquisa do Estado de São Paulo, Brazil.

\section{References}

1. McCuskey S, Urbaschek R, Urbaschek B: The microcirculation during endotoxemia. Cardiovasc Res 1996, 32:752-763.

2. Hinshaw LB: Sepsis/septic shock: participation of the microcirculation: an abbreviated review. Crit Care Med 1996, 24:1072-1078.

3. Friedman G, Silva E, Vincent JL: Has the mortality of septic shock changed with time? Crit Care Med 1998, 26:2078-2086.

4. Task Force of the American College of Critical Care Medicine, Society of Critical Care Medicine: Practice parameters for hemodynamic support of sepsis in adult patients in sepsis. Crit Care Med 1999, 27:639-660.

5. Armistead CW Jr, Vincent JL, Preiser JC, De Backer D, Le Minh Thuc: Hypertonic saline solution-hetastarch for fluid resuscitation in experimental septic shock. Anesth Analg 1989, 69:714-720.

6. Sakka SG, Meier-Hellmann A, Reinhart K: Do fluid administration and reduction in norepinephrine dose improve global and splanchnic haemodynamics? Br J Anaesth 2000, 84:758-762.

7. Hayes MA, Timmins AC, Yau EHS, Palazzo M, Hinds CJ, Watson $D$ : Elevation of systemic oxygen delivery in the treatment of critically ill patients. N Engl J Med 1994, 330:1717-1722.
8. Gomersall CD, Joynt GM, Freebairn RC, Hung V, Buckley TA, Oh TE: Resuscitation of critically ill patients based on the results of gastric tonometry: a prospective, randomized, controlled trial. Crit Care Med 2000, 28:607-614.

9. Schlichting E, Lyberg T: Monitoring of tissue oxygenation in shock: an experimental study in pigs. Crit Care Med 1995, 23:1703-1710.

10. Knichwitz G, Rötker J, Möllhoff T, Richter KD, Brussel T: Continuous intramucosal $\mathrm{PCO}_{2}$ measurement allows the early detection of intestinal malperfusion. Crit Care Med 1998, 16:1550-1557.

11. Lebuffe G, Decoene C, Pol A, Prat A, Vallet B: Regional capnometry with air-automated tonometry detects circulatory failure earlier than conventional hemodynamics after cardiac surgery. Anesth Analg 1999, 89:1084-1090.

12. Baker JW, Deitch EA, Li M, Berg RD, Specian RD: Hemorrhagic shock induces bacterial translocation from the gut. $J$ Trauma 1988, 28:896-906.

13. Deitch EA, XU D, Franko L, Ayala A, Chaudry IH: Evidence favouring the role of gut as a cytokine-generating organ in rats subjected to hemorrhagic shock. Shock 1994, 1:141-146.

14. Doglio GR, Pusajo JF, Egurrola MA, Bonfigli GC, Parra C, Vetere L, Hernandez MS, Fernandez S, Palizas F, Gutierrez G: Gastric mucosal $\mathrm{pH}$ as a prognostic index of mortality in critically ill patients. Crit Care Med 1991, 19:1037-1040.

15. Marik PE: Gastric mucosal pH. A better predictor of multiorgan dysfunction syndrome and death than oxygen-derived variables in patients with sepsis. Chest 1993, 104:225-229.

16. Deitch EA: Animal models of sepsis and shock: a review and lessons learned. Shock 1998, 9:1-11.

17. Rivers E, Nguyen B, Havstad S, Ressler J, Muzzin A, Knoblich B, Peterson E, Tomlanovich M: Early Goal-Directed Therapy Collaborative Group. Early goal-directed therapy in the treatment of severe sepsis and septic shock. N Engl J Med 2001, 345:1368-1377.

18. Vallet B, Lund N, Curtis SE, Kelly D, Cain SM: Gut and muscle tissue $\mathrm{PO}_{2}$ in endotoxemic dogs during shock and resuscitation. $J$ Appl Physiol 1994, 76:793-800.

19. De Backer $D$, Zhang $H$, Manikis $P$, Vincent JL: Regional effects of dobutamine in endotoxic shock. J Surg Res 1996, 65:93-100.

20. Silva E, De Backer D, Creteur J, Vincent JL: Effects of fluid challenge on gastric mucosal PCO2 in septic patients. Intensive Care Med 2004, 30:423-429.

21. Guzman JA, Lacoma FJ, Kruse JÁ: Gastric and esophageal intramucosal PCO2 (PiCO2) during endotoxemia: assessment of raw $\mathrm{PiCO} 2$ and $\mathrm{PCO} 2$ gradients as indicators of hypoperfusion in a canine model of septic shock. Chest 1998, 113:1078-1083.

22. Antonsson JB, Boyle CC III, Kruithoff KL, Wang HL, Sacristan E, Rothschild HR, Fink MP: Validation of tonometric measurement of gut intramural $\mathrm{pH}$ during endotoxemia and mesenteric occlusion in pigs. Am J Physiol 1990, 259:G519-G523.

23. Nelson DP, Samsel RW, Wood LD, Schumacker PT: Pathological supply dependence of systemic and intestinal 02 uptake during endotoxemia. J App/ Physiol 1988, 64:2410-2419.

24. Kellum JA, Rico P, Garuba AK, Pinsky MR: Accuracy of mucosal $\mathrm{pH}$ and mucosal-arterial carbon dioxide tension for detecting mesenteric hypoperfusion in acute canine endotoxemia. Crit Care Med 2000, 28:462-466.

25. Uusaro A, Russell JA, Walley KR, Takala J: Gastric-arterial PCO2 gradient does not reflect systemic and splanchnic hemodynamics or oxygen transport after cardiac surgery. Shock 2000, 14:13-17.

26. Duranteau J, Sitbon P, Teboul JL, Vicaut E, Anguel N, Richard C Samii K: Effects of epinephrine, norepinephrine, or the combination of norepinephrine and dobutamine on gastric mucosa in septic shock. Crit Care Med 1999, 27:893-900.

27. Tugtekin IF, Radermacher $P$, Theisen $M$, Matejovic $M$, Stehr $A$ Ploner F, Matura K, Ince C, Georgieff M, Trager K: Increased ilealmucosal-arterial $\mathrm{PCO} 2$ gap is associated with impaired villus microcirculation in endotoxic pigs. Intensive Care Med 2001, 27:757-766.

28. Nakajima Y, Baudry N, Duranteau J, Vicaut E: Microcirculation in intestinal villi : a comparison between hemorrhagic and endotoxin shock. Am J Respir Crit Care Med 2001, 164:1526-1530.

29. VanderMeer TJ, Wang H, Fink MP: Endotoxemia causes ileal mucosal acidosis in the absence of mucosal hypoxia in a nor- 
modynamic porcine model of septic shock. Crit Care Med 1995, 23:1217-1226.

30. Revelly JP, Ayuse T, Brienza N, Fessler HE, Robotham JL: Endotoxic shock alters distribution of blood flow within the intestinal wall. Crit Care Med 1996, 24:1345-1351.

31. Baum TD, Wang H, Rothschild HR, Gang D, Fink M: Mesenteric oxygen metabolism, ileal mucosal hydrogen ion concentration, and tissue edema after crystalloid or colloid resuscitation in porcine endotoxic shock: comparison of Ringer's lactate and 6\% Hetastarch. Circ Shock 1990, 30:385-397.

32. Poli de Figueiredo LF, Cruz RJ Jr, Yada-Langui MM, Silva E, Rocha e Silva M: Comparison of local and systemic markers of digestive tract dysoxia induced by hemorrhage and rapid ressuscitation in dogs. Shock 2001, 15:47.

33. Fink MP, Cohn SM, Lee PC, Rothschild HR, Deniz YF, Wang $\mathrm{H}$, Fiddian-Green RG: Effect of lipopolysaccharide on intestinal intramucosal hydrogen ion concentration in pigs: Evidence of gut ischemia in a normodynamic model of septic shock. Crit Care Med 1989, 17:641-646.

34. Drazenovic R, Samsel RW, Wylan ME, Doerschuk CM, Schumacker PT: Regulation of perfused capillary density in canine intestinal mucosa during endotoxemia. J Appl Physiol 1992, 72:259-265.

35. Fink MP, Kaups KL, Wang HL, Rothschild HR: Maintenance of superior mesenteric arterial perfusion prevents increased intestinal mucosal permeability in endotoxic pigs. Surgery 1991, 110:154-160.

36. Kirton OC, Windsor J, Wedderburn R, Hudson-Civetta J, Shatz DV, Mataragas NR, Civetta JM: Failure of splanchnic resuscitation in the acutely injured trauma patient correlates with multiple organ system failure and length of stay in the ICU. Chest 1998, 113:1064-1069. 